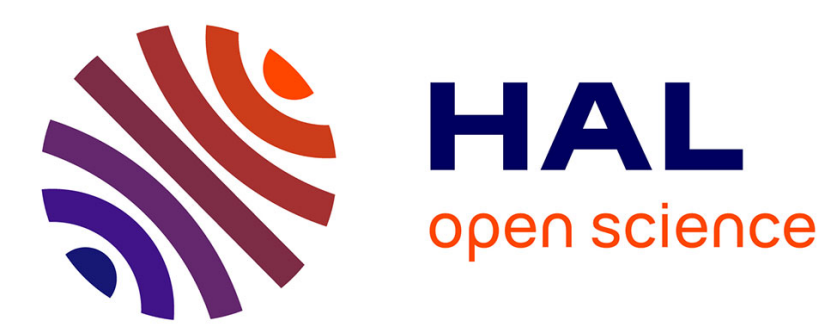

\title{
Fire behavior of halogen-free flame retardant electrical cables with the cone calorimeter
}

\author{
R. Meinier, Rodolphe Sonnier, P. Zavaleta, S. Suard, Laurent Ferry
}

\section{To cite this version:}

R. Meinier, Rodolphe Sonnier, P. Zavaleta, S. Suard, Laurent Ferry. Fire behavior of halogen-free flame retardant electrical cables with the cone calorimeter. Journal of Hazardous Materials, 2018, 342, pp.306-316. 10.1016/j.jhazmat.2017.08.027 . hal-02871833

\section{HAL Id: hal-02871833 \\ https://hal.science/hal-02871833}

Submitted on 3 Jun 2021

HAL is a multi-disciplinary open access archive for the deposit and dissemination of scientific research documents, whether they are published or not. The documents may come from teaching and research institutions in France or abroad, or from public or private research centers.
L'archive ouverte pluridisciplinaire HAL, est destinée au dépôt et à la diffusion de documents scientifiques de niveau recherche, publiés ou non, émanant des établissements d'enseignement et de recherche français ou étrangers, des laboratoires publics ou privés.

\section{(ㅇ)(1) $\$$}

Distributed under a Creative Commons Attribution - NonCommercial - NoDerivatives| 4.0 


\title{
Fire behavior of halogen-free flame retardant electrical cables with the cone calorimeter
}

\author{
Romain Meinier $^{\mathrm{a}}$, Rodolphe Sonnier ${ }^{\mathrm{a}, *}$, Pascal Zavaleta ${ }^{\mathrm{b}}$, Sylvain Suard ${ }^{\mathrm{b}}$, Laurent Ferry $^{\mathrm{a}}$ \\ a Ecole des Mines d'Alès, Centre des Matériaux des Mines d'Alès - Pôle Matériaux Polymères Avancés, 6 Avenue de Clavières, 30319 Alès Cedex, France \\ ${ }^{\mathrm{b}}$ Institut de Radioprotection et de Sûreté Nucléaire (IRSN), PSN-RES, SA2I, LEF, Cadarache, St Paul-Lez-Durance Cedex, 13115, France
}

\author{
H I G H L I G H T S
}

- Halogen-free electrical cables are studied using cone calorimeter tests.

- The influence of external heat flux and spacing is highlighted.

- Time-to-ignition is only dependent on the sheath properties.

- A critical heat flux corresponds to a significant change in fire hazard.

- Spacing between cables has a variable effect on fire properties.

\begin{abstract}
A B S T R A C T
Fires involving electrical cables are one of the main hazards in Nuclear Power Plants (NPPs). Cables are complex assemblies including several polymeric parts (insulation, bedding, sheath) constituting fuel sources. This study provides an in-depth characterization of the fire behavior of two halogen-free flame retardant cables used in NPPs using the cone calorimeter. The influence of two key parameters, namely the external heat flux and the spacing between cables, on the cable fire characteristics is especially investigated. The prominent role of the outer sheath material on the ignition and the burning at early times was highlighted. A parameter of utmost importance called transition heat flux, was identified and depends on the composition and the structure of the cable. Below this heat flux, the decomposition is limited and concerns only the sheath. Above it, fire hazard is greatly enhanced because most often nonflame retarded insulation part contributes to heat release. The influence of spacing appears complex, and depends on the considered fire property.
\end{abstract}

Keywords:

Halogen-free flame retardant

Thermally thick behavior

Fire behavior

Cone calorimeter

Cable spacing

\section{Introduction}

Several thousand kilometres of electrical cables are present throughout the nuclear power plants (NPPs). Power cables are used for instance for supplying electricity to the pumps, turbines, transformers, heaters, or to the numerous electrical cabinets contained in NPPs [1]. Furthermore, many cable trays also contain instrumentation and control cables. The former are used for digital or analogic transmission for various types of transducers while the latter serve for example for controlling valves or operating relays and contactors.

A serious cable fire occurred at the Browns Ferry NPP in 1975 [2] resulting in loss of the emergency core cooling system of unit

\footnotetext{
* Corresponding author.

E-mail address: rodolphe.sonnier@mines-ales.fr (R. Sonnier).
}

1. Ever since, many efforts have been made on the most recent nuclear installations all over the world to enhance the prevention of cable fires, for instance by using flame retardant materials in cables. Nevertheless, nearly seventy fire events from nuclear power plants (NPPs) involving electrical cables as fuel were recorded in the current OECD FIRE Database between the late 1980s and the end of 2010 [3].

Cable fires are therefore one of the main fire hazards which may affect the safety of NPPs. The assessment of such fire hazard and of their consequences largely relies on the use of fire models able to forecast the fire spread over cable trays. Experimental research programmes on cable fires were conducted over the past four decades for providing data at both small and large scale in order to develop and to validate some fire models. For instance, the Lee correlation [4] was built from the results of large-scale horizontal cable tray fire tests [5] and the ones on fire behavior of cable samples obtained at small-scale [6]. This correlation thus aims at assessing the peak 
of heat release rate (HRR) of horizontal cable trays fires by using the HRR peak per unit area for cable samples measured in the fire propagation apparatus [7] or in the cone calorimeter [8] under an irradiance of $60 \mathrm{~kW} / \mathrm{m}^{2}$. In addition, the engineering FLASH-CAT model [1] was proposed to assess the time evolutions of the HRR of a fire spreading over horizontal ladder cable trays located away from wall and ceiling. This model needs as input parameters the physical and thermal properties of the electrical cables as well as its main fire characteristics (ignition delay, HRR per unit area. ..), all determined at small-scale. The FLASH-CAT model was validated in the scope of the CHRISTIFIRE programme [1] which involved both large-scale horizontal cable trays fires in open atmosphere conditions and small-scale characterizations. Furthermore, small scale characterizations of the electrical cables [9] are also essential for the development of pyrolysis models $[10,11]$. These last ones are currently implemented in fire field models for a detailed forecasting of the fire spread over cable trays.

In the scope of the OECD PRISME-2 project [12], additional realscale cable tray fire tests were carried out in open atmosphere $[13,14]$. These fire tests involved new configurations such as horizontal and slanted cable trays, both supported by a wall and filled with halogen-free flame retardant (HFFR) cable-types used in NPPs. These cable-types showed a strong impact on the fire characteristics such as the ignition delay, the fire growth rate and the effective heat of combustion (EHC) $[13,14]$. These original experimental results clearly highlighted the need of complementary fire tests at small and large-scale to a better understanding of HFFR cable fire behavior and to perform a complete validation of fire models. Moreover, the cable arrangement, which is an important parameter in NPPs [15], was not taken into account in the scope of these fire tests. So there is also a particular interest for investigate the effect of cable spacing on the fire characteristics.

Consequently, the current study first aims at investigating the role of the different cable components on the main fire characteristics in the case of HFFR cables based on ethylene-vinyl acetate copolymer and polyethylene (EVA-PE) matrix. The structure and composition of cables were analysed in detail and the thermophysical and flammability properties of the outer sheath were determined. Then the burning behavior of the two cables was studied using the cone calorimeter. Time-to-ignition, HRR and EHC were measured for different external heat fluxes. An attempt was made to relate these parameters to the properties of the cable component and more especially the outer sheath. Lastly the effect of cable spacing on the time-to-ignition and the fire characteristics was investigated.

\section{Experimental approaches}

\subsection{Materials}

Two halogen-free flame retardant cables are used in the present study. The first, named cable $\mathrm{A}$, has an external diameter and a mass per unit length of $12 \mathrm{~mm}$ and $0.21 \mathrm{~kg} / \mathrm{m}$ respectively. The second one (cable B) has an external diameter of $21 \mathrm{~mm}$, and a mass per unit length of $0.67 \mathrm{~kg} / \mathrm{m}$. SEM-EDX (scanning electron microscopy coupled energy-dispersive X-ray spectroscopy) observations carried out on sheath materials evidence the presence of aluminum. The decomposition of sheath (the outer layer) under nitrogen flow starts at $200^{\circ} \mathrm{C}$. This outcome confirms that the mineral flame retardant is probably aluminum hydroxide $(\mathrm{ATH})$, the most used metallic hydroxide in wire and cable industry [16]. Considering the weight residue obtained from anaerobic pyrolysis in thermogravimetric analysis (around $40 \mathrm{wt} \%$ ) it is possible to assess the fillers content: between 60 and $62 \mathrm{wt} \%$ for both cable-types. Indeed, polymer is fully decomposed and ATH leaves a residue of $35 \mathrm{wt} \%$. This is typical of sheath formulations for such cable-type. A more detailed description of the cables is provided in the results section.

\subsection{Cone calorimetry}

Fire behavior was studied using a cone calorimeter [8]. There have been a large number of studies that characterized cables under such fire test equipment $[1,17-21]$. The first question arising when testing cables is the preparation of specimens. Recommendations from ISO 5660 standard were followed except the use of a grid. Cables were cut in pieces of $10 \mathrm{~cm}$ long. These cable samples were arranged one against one other without space as shown in Fig. 1. 8 and 5 cable samples were used respectively for cables A and B. Specimen were wrapped in aluminum foil and insulated by rock wool. The samples were exposed to various heat fluxes in wellventilated conditions (air volume flow rate of $24 \mathrm{~L} / \mathrm{s}$ ) in the presence of a spark igniter to force the ignition. The distance between the cable samples and the cone was fixed to $25 \mathrm{~mm}$. The HRR was determined by oxygen depletion according to Huggett's relation ( $1 \mathrm{~kg}$ of consumed oxygen corresponds to $13.1 \mathrm{MJ}$ of released energy) [22]. In some experiments, the temperature of the upper surface of the samples was measured during cone calorimeter test using an infrared camera (Optris) to assess the temperature at ignition. For these experiments, the distance between the cable samples and the cone was fixed to $60 \mathrm{~mm}$ (instead of $25 \mathrm{~mm}$ ) to allow a correct measurement (The inclination of the infrared camera must be of few degrees relative to the perpendicular position).

The use of a grid is recommended to avoid the distortion of cables during the test [8]. However, a grid reduces the heat flux absorbed by the sample and will, for instance, influence the timeto-ignition. The data on this last parameter are intended to be used in simple models for forecasting of real cable fire. Therefore in this work, the grid was removed.

\subsection{Pyrolysis-combustion flow calorimetry}

The flammability of each component of cables was investigated using a pyrolysis combustion flow calorimeter (PCFC from Fire Testing Technology, UK) which was developed by Lyon and Walters [23]. The sample ( $\pm 0.5 \mathrm{mg})$ was heated from 80 to $750^{\circ} \mathrm{C}$ at $1^{\circ} \mathrm{C} / \mathrm{s}$

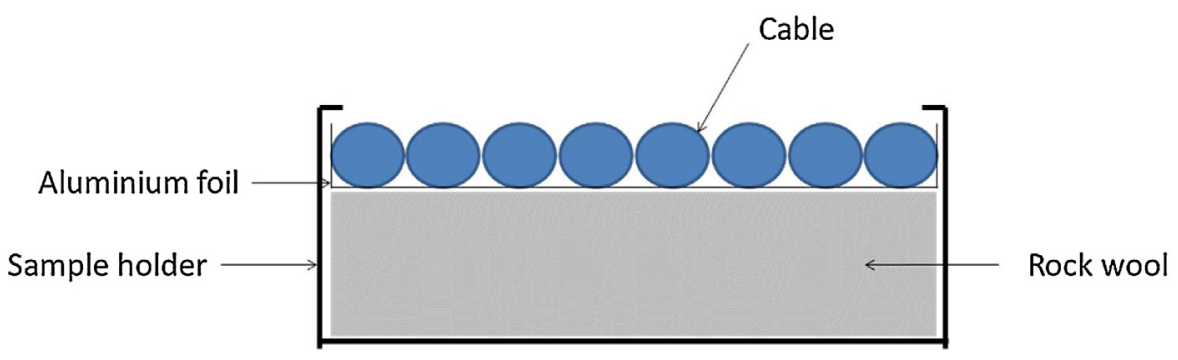

Fig. 1. Positioning of cables into the sample holder. 


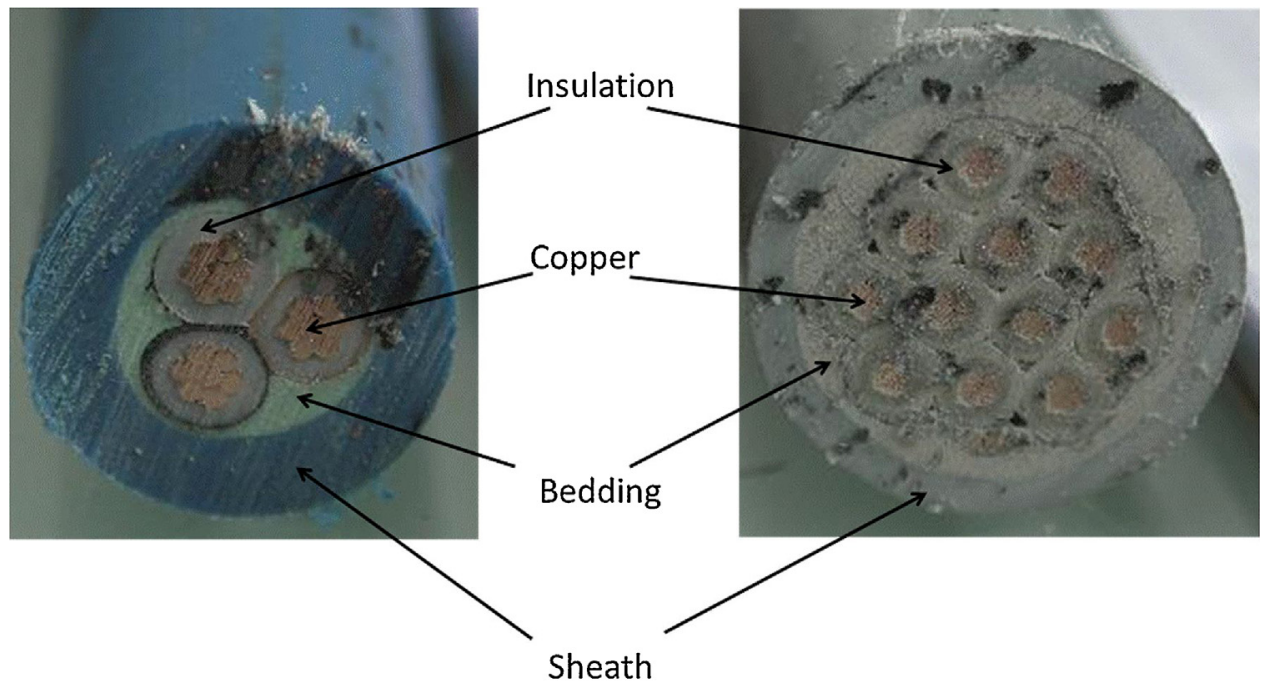

Fig. 2. Description of cables A (left) and B (right).

in a pyrolyzer under nitrogen flow and the degradation products were sent to a combustor where they are mixed with oxygen in excess at $900^{\circ} \mathrm{C}$. In such conditions, these products were fully oxidized. The HRR was then calculated by oxygen depletion as in cone calorimetry.

\subsection{Thermogravimetric analysis}

Thermogravimetric analyses (TGA) were performed on sheath and insulation materials using a Setsys Evolution apparatus (Setaram). The samples $(10 \pm 2 \mathrm{mg})$ were heated under nitrogen flow $(100 \mathrm{~mL} / \mathrm{min})$ at a heating rate equal to $1^{\circ} \mathrm{C} / \mathrm{s}$ from room temperature to $900^{\circ} \mathrm{C}$.

\subsection{Thermophysical properties of sheath materials}

Additional analyses were performed on sheath materials only at room temperature. Density, $\rho\left(\mathrm{kg} / \mathrm{m}^{3}\right)$, was measured using a helium Pycnometer (Micromeritics AccuPyc 1330). Specific heat, c (J/kg.K), was measured using a Perkin Elmer differential scanning calorimetry (Stepscan software). The heat diffusivity, $\mathrm{D}\left(\mathrm{m}^{2} / \mathrm{s}\right)$, was measured using a Laser Flash apparatus (XFA600 from Linseis). Sheaths were flattened by thermocompression and then specimens were stamped from flat sheets and coated with graphite on both surfaces. Measurements were carried out in vacuum. Values were averaged over five measurements. The heat conductivity, $\lambda$ $(\mathrm{W} / \mathrm{m} . \mathrm{K})$, was calculated from D, $\rho$ and c according to the Eq. (1):

$\lambda=\mathrm{D} \times \rho \times \mathrm{C}$

\section{Results and discussion}

\subsection{Description of cables}

Cables are very complex materials containing several constituent parts (sheath, bedding, insulation and copper). The flammability of the whole cable depends on the chemical composition and morphology of each constituent part as well as on their amount and the cable structure. Fig. 2 shows the cross-section of the cables A and B with their main components.

Each component was separated, weighted and analysed using PCFC to calculate its contribution to the heat release (called heat fraction). The heat fraction of component $\mathrm{i}$ is defined as follows (Eq. (2)):

heatfraction $_{i}=\frac{T H R_{i} \times W_{i}}{\sum_{j} T H R_{j} \times W_{j}}$

With $\mathrm{THR}_{\mathrm{i}}$ and $\mathrm{W}_{\mathrm{i}}$ are respectively the heat release of the component $\mathrm{i}$ (in $\mathrm{kJ} / \mathrm{g}$ ) and the weight fraction of the component $\mathrm{i}$.

The cable A contains only four components but the cable B can be divided into seven components. Three of them were not perfectly identified but they have a negligible contribution to weight and heat release. One component is an aluminum film, others represent a very small weight fraction with a moderate heat of combustion - $16 \mathrm{~kJ} / \mathrm{g}$ or less, probably poly(ethylene terephthalate) film. Moreover they burn only when the flame is already developed (when the sheath is degrading) and they are too thin to prevent the heating of the underlying PE insulation. Therefore they were not considered in the following analysis. Table 1 provides the weight and heat fractions of the four main components for both cables, representing more than $95 \%$ of the weight and of the heat release. Compared to the other non-metallic components, the contribution of sheath is the most important for the cable A. The weight is more fairly distributed between the four main components of the cable B. Sheath and insulation each represent around $40 \%$ of the heat release for this last cable-type.

\subsection{Ignition of cables}

In order to assess if the sheath controls alone the ignition of the cable, experimental time-to-ignition will be compared to the values calculated from two different models (see below). For this purpose, some properties of the sheath materials are needed. Table 2 provides the main data. The properties of both materials are similar. The major difference concerns the sheath thickness.

Table 1

Description of cables A and B with the weight and heat fraction of main components.

\begin{tabular}{llllll}
\hline & \multicolumn{2}{l}{ Cable A } & & & \multicolumn{2}{l}{ Cable B } \\
\cline { 2 - 3 } \cline { 5 - 6 } \cline { 5 - 6 } & Weight fraction & Heat fraction & & Weight fraction & Heat fraction \\
\hline Sheath & 0.538 & 0.721 & 0.224 & 0.413 \\
Bedding & 0.082 & 0.064 & 0.173 & 0.158 \\
Insulation & 0.095 & 0.215 & & 0.205 & 0.408 \\
Copper & 0.285 & 0 & 0.366 & 0 \\
Total & 1 & 1 & 0.968 & 0.979 \\
\hline
\end{tabular}


Table 2

Main properties of sheath materials for cables A and B.

\begin{tabular}{lll}
\hline & Cable A & Cable B \\
\hline Thickness $\mathrm{L}_{0}(\mathrm{~mm})$ & 2.5 & 2 \\
Specific heat $\mathrm{c}(\mathrm{J} / \mathrm{g} . \mathrm{K})$ & 1.52 & 1.59 \\
Density $\rho\left(\mathrm{g} / \mathrm{cm}^{3}\right)$ & 1.540 & 1.476 \\
Heat diffusivity $\left(\mathrm{mm}^{2} / \mathrm{s}\right)$ & 0.216 & 0.169 \\
Heat conductivity $\lambda(\mathrm{W} / \mathrm{cm} . \mathrm{K})$ & $5.03 \times 10^{-3}$ & $3.82 \times 10^{-3}$ \\
Temperature to ignition $T_{\text {ign }}\left({ }^{\circ} \mathrm{C}\right)$ & 420 & 390 \\
\hline
\end{tabular}

Table 3

Critical heat flux calculated for cables A and B according to thermally thin or thermally thick models.

\begin{tabular}{lll}
\hline Critical heat flux $\left(\mathrm{kW} / \mathrm{m}^{2}\right)$ & Cable A & Cable B \\
\hline Thermally thin cable & 34.2 & 25.7 \\
Thermally thick cable & 12.8 & 10.6 \\
\hline
\end{tabular}

The time-to-ignition of flat sheets in cone calorimeter changes with the external heat flux accordingly to Eqs. (3) and (4) for respectively thin and thick specimens [24-26].

$t_{\text {ign }}=L_{0} \rho c\left(\frac{T_{\text {ign }}-T_{0}}{\dot{q}^{\prime \prime}-C H F}\right)$

$t_{i g n}=\frac{\pi}{4} \lambda \rho c\left(\frac{T_{i g n}-T_{0}}{\dot{q}^{\prime}-C H F}\right)^{2}$

With $\dot{q}$ " the external heat flux $\left(\mathrm{kW} / \mathrm{m}^{2}\right)$, CHF the critical heat flux $\left(\mathrm{kW} / \mathrm{m}^{2}\right), \mathrm{T}_{0}$ the room temperature $\left(28^{\circ} \mathrm{C}\right)$ and $\mathrm{L}_{0}, \mathrm{c}, \lambda, \rho$ and $\mathrm{T}_{\text {ign }}$ the material properties defined in Table 2 . In order to identify the thermal behavior of the cables, critical heat flux (CHF) can be calculated by plotting the curves $\frac{1}{\sqrt{t_{i g n}}}=f\left(\dot{q}^{\prime \prime}\right)$ or $\frac{1}{t_{\text {ign }}}=f\left(\dot{q}^{\prime \prime}\right)$ respectively for thermally thick and thermally thin models. Critical heat flux is then the value of $\dot{q}$ " for which the ordinate is null (i.e. below the critical heat flux, no ignition occurs). Table 3 provides the critical heat flux for both cases according to the two models. The values calculated from thermally thin model appear to be probably too high. Indeed, formulations (EVA filled with $60 \mathrm{wt} \%$ of ATH or MDH - magnesium hydroxide) similar to that of the sheath have already been tested using cone calorimeter and ignition was observed even at $25 \mathrm{~kW} / \mathrm{m}^{2}$ [27]. The critical heat flux according to thermally thick model is similar for both cables and quite reasonable. Fontaine et al. found a similar value $\left(10.5 \mathrm{~kW} / \mathrm{m}^{2}\right)$ for a $10 \mathrm{~mm}$ diameter cable whose sheath mainly contains EVA and ATH (i.e. very similar to cable A) studied in the same configuration [28].

To confirm the thermally thick behavior of the cable, it is possible to compare the experimental times-to-ignition to the values calculated from the Eqs. (3) and (4) by using the calculated critical heat flux and the properties measured for sheath materials (Table 2). Figs. 3 and 4 provide this comparison for cables A and $B$ respectively. In both cases, thermally thick model allows fitting well the experimental values. On the contrary, the thin model fails to predict accurately the time-to-ignition for all heat fluxes. Such results are in agreement with previous works about various types of cables [28-32]. This result also shows that the ignition depends only on the properties of the sheath. Indeed, TTI calculated from Eq. (4) were obtained considering only the thermophysical properties of the sheath (and not of the whole cable).

It is noteworthy that Eq. (4) remains suitable for cables although the surface is not flat as for a sheet. No correction seems necessary to take into account the curvature of cables as proposed by Delichatsios [33].

\subsection{Heat release rate}

Figs. 5 and 6 represent the HRR curves at various heat fluxes for cables A and B respectively. The sheath is of course the first component to be degraded. The burning of EVA-PE filled with ATH is well documented. EVA and PE are non-charring polymers. Therefore these polymers are pyrolyzed in fuels feeding the flame while ATH releases water. Only alumina remains in condensed phase, forming a mineral layer able to limit the heat transfer. Other components of the cables, especially PE insulation, are progressively heated. If the temperature reaches the pyrolysis temperature, PE from insulation can also feed the flame and promote the fire propagation.

After ignition, the HRR increases sharply up to a first peak (pHRR1). Then the HRR decreases slowly during several hundreds of seconds. For low fluxes $\left(38 \mathrm{~kW} / \mathrm{m}^{2}\right.$ for the cable $\mathrm{A}$ and 35 and $50 \mathrm{~kW} / \mathrm{m}^{2}$ for the cable B) this decrease leads to flame out. For

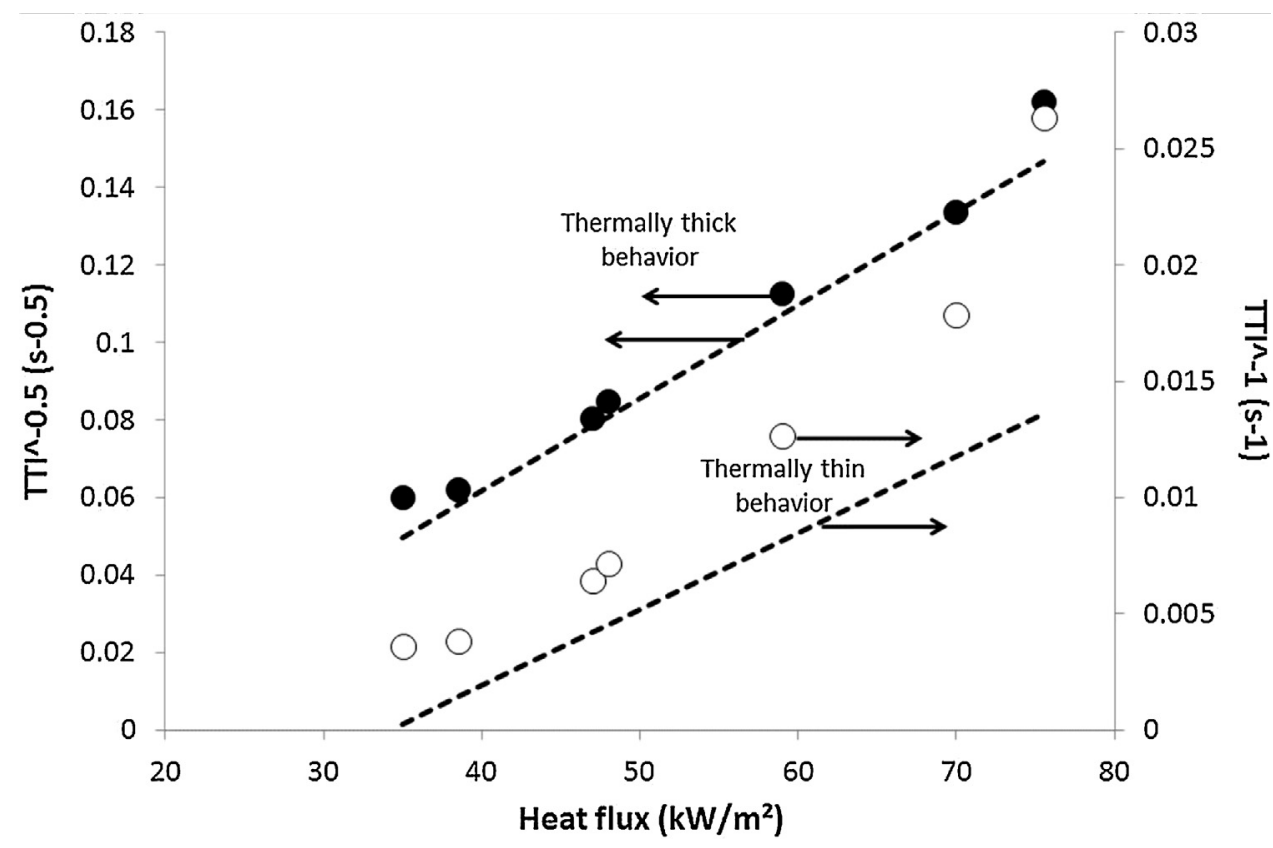

Fig. 3. Experimental versus modelled time-to-ignition values for cables A - black circles: experimental data, dotted lines: calculated data. 


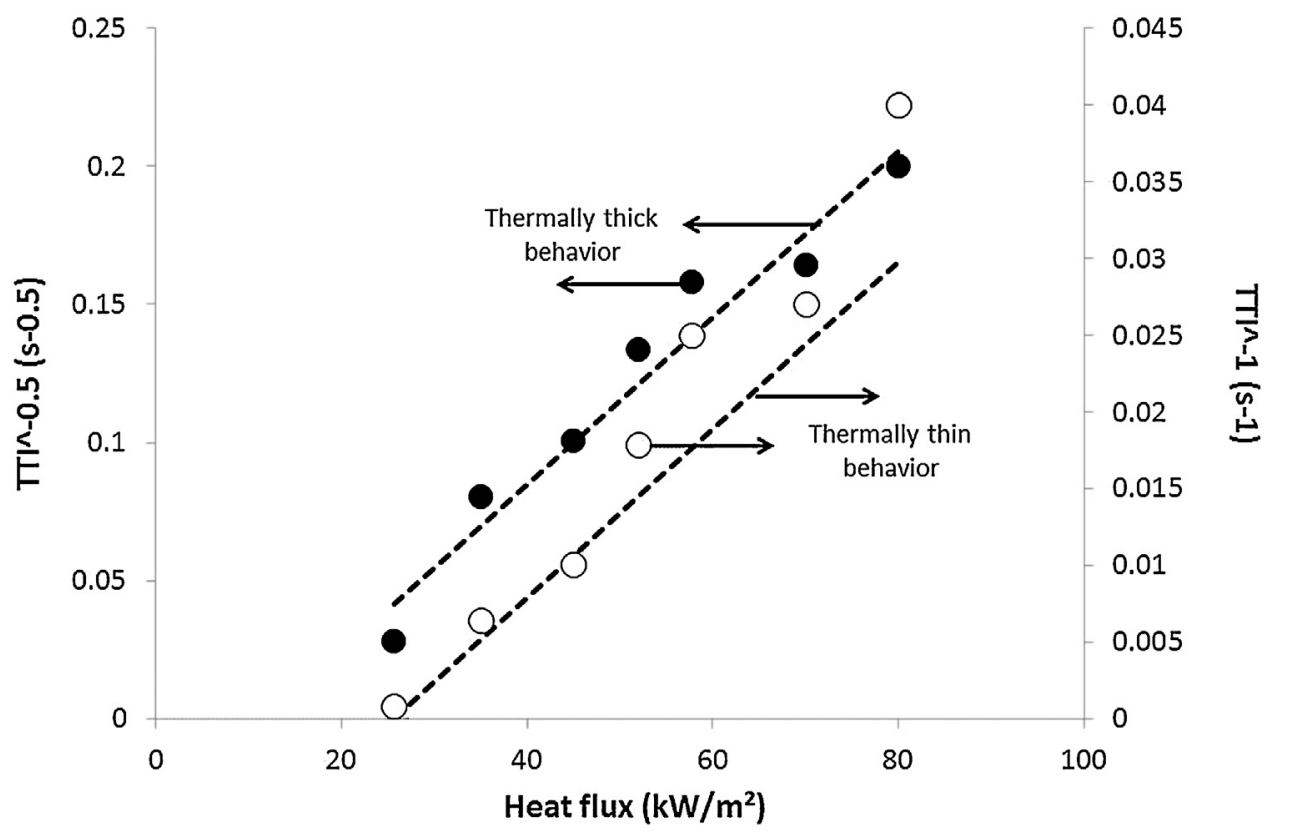

Fig. 4. Experimental versus modelled time-to-ignition values for cables B - circles: experimental data, dotted lines: calculated data.

higher heat flux levels, the burning behavior is somewhat different. Indeed, after 500-1000s, the decomposition is accelerated, the heat release rate increases and leads to a second peak (pHRR2) higher than the first one except for the cable B exposed at $80 \mathrm{~kW} / \mathrm{m}^{2}$. This peak occurs earlier when increasing the heat flux. However, during this second period, distortion of cables is sometimes observed because no grid was used. This random phenomenon can modify the surface exposed to the flame (flame may reach the bottom of the cables). Therefore, the intensity of this second peak is not reproducible and does not follow a consistent tendency. All these remarks are common for both cables.

For both cables pHRR1 increases when increasing heat flux (Fig. 7). However, there is a strong difference between cables. The increase in pHRR1 is relatively slow for cable A and faster for cable
B. Therefore, at high heat flux, the pHRR1 becomes significantly higher for cable B. Note that pHRR1 for cable A is in the range $90-150 \mathrm{~kW} / \mathrm{m}^{2}$ in good agreement with previous findings from Fontaine and coworkers for a similar cable [28]. Time to pHRR1 also tends to decrease when increasing heat flux (Figs. 5 and 6). But the difference between time-to-ignition and time to pHRR1 ranges between 20 and $50 \mathrm{~s}$ for heat flux higher than $40 \mathrm{~kW} / \mathrm{m}^{2}$. Only at low heat flux, this difference tends to increase but remains lower than $100 \mathrm{~s}$.

The pHRR1 is followed by a sharp and continuous decrease. This may be related to the accumulation of mineral fillers (alumina from the thermal decomposition of ATH) on the cable top by ablation of non-charring polymers from the sheath [34]. The mineral layer is able to slow down the heat transfer from the flame to

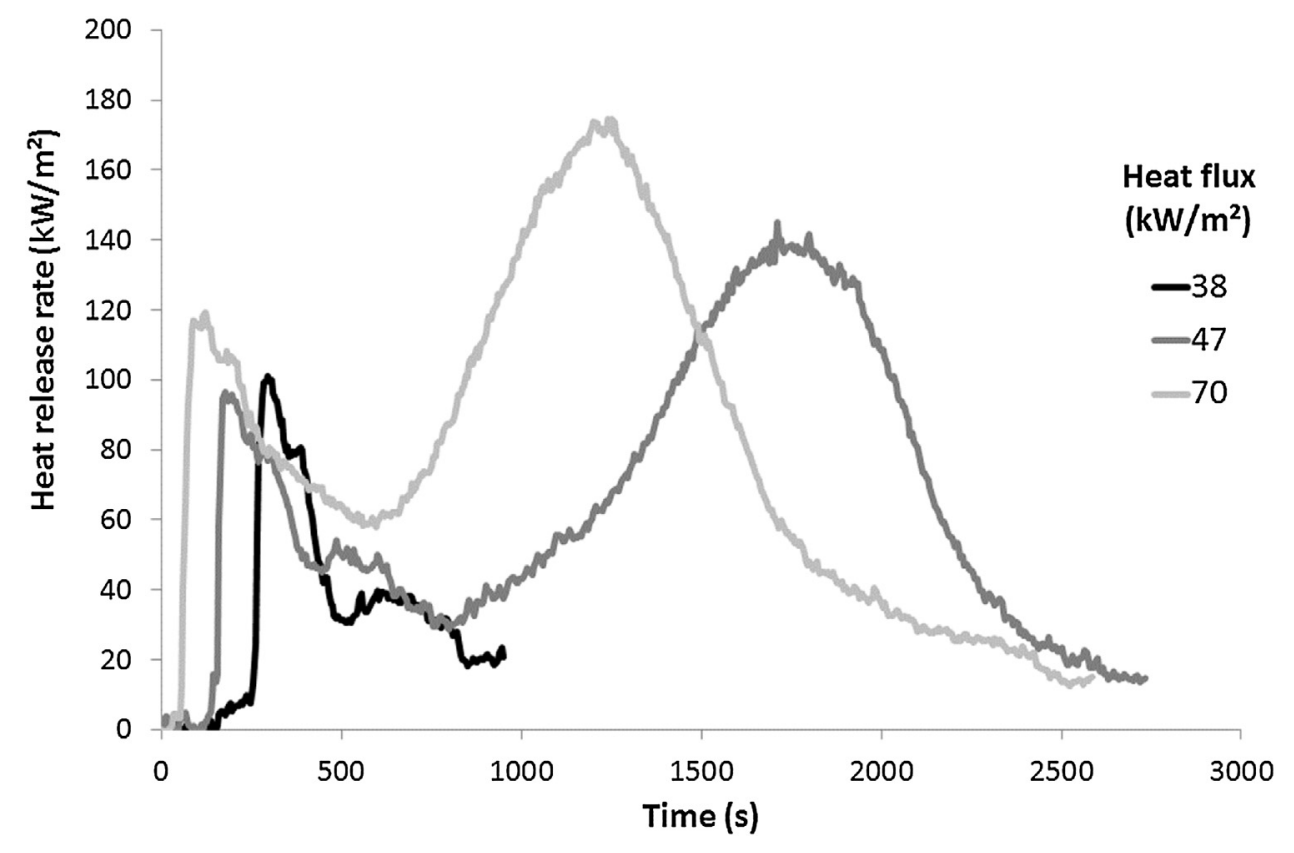

Fig. 5. Heat release rate for cables A at different heat fluxes. 


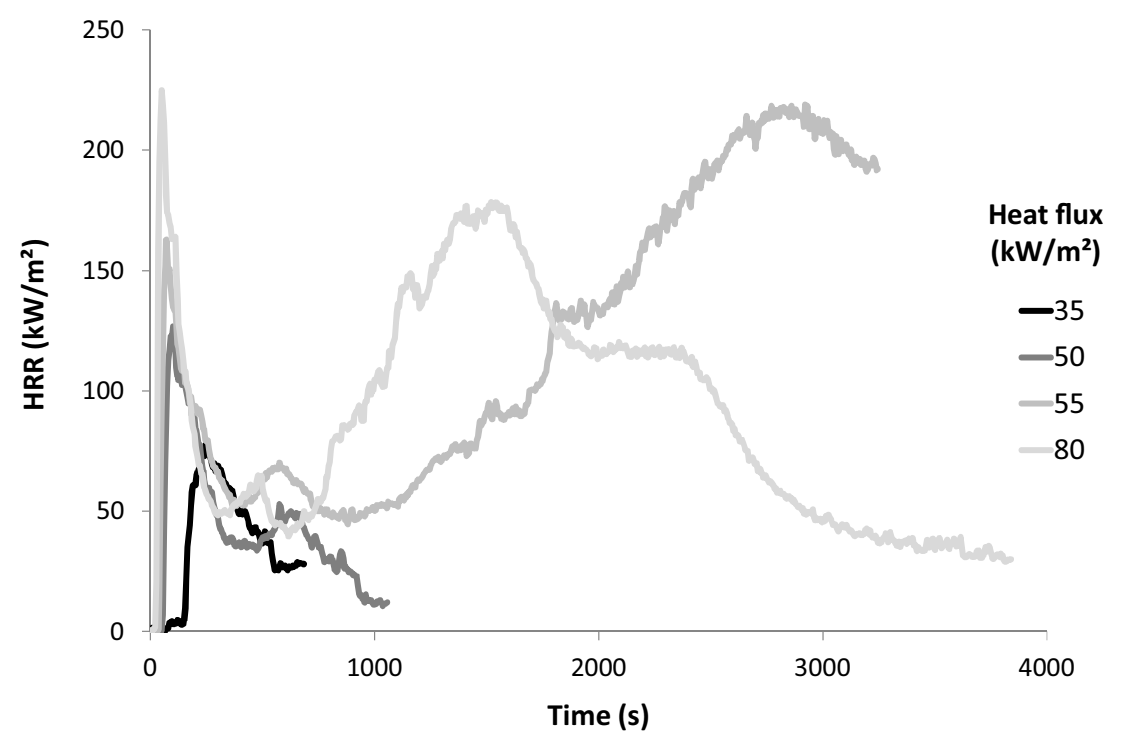

Fig. 6. Heat release rate for cables B at different heat fluxes.

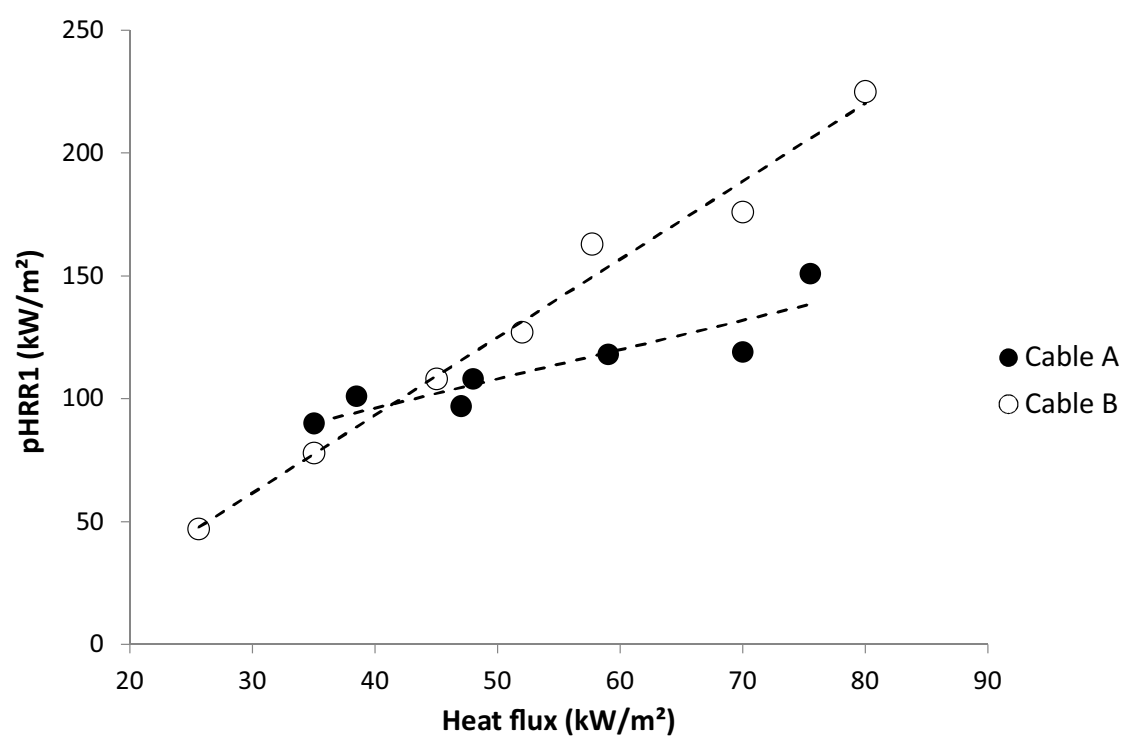

Fig. 7. pHRR1 for cables A and B at different heat fluxes.

the underlying polymer (i.e. PE and EVA from the sheath and PE from insulation) and then the pyrolysis rate decreases. Nevertheless, as already mentioned, at high heat flux, a further increase in HRR occurs after 500-1000s leading to a second pHRR. Obviously the decomposition of the whole cable becomes much more significant as revealed by the total heat release (Fig. 8). THR increases continuously when increasing heat flux. Nevertheless, at low heat flux, if flame out is observed without pHRR2, THR remains limited $\left(<50 \mathrm{MJ} / \mathrm{m}^{2}\right)$. As soon as the pHRR2 occurs, THR becomes much higher: higher than 180 and $300 \mathrm{MJ} / \mathrm{m}^{2}$ for cables A and B respectively. It means that not only the polymers from the sheath but also the PE from insulation are pyrolyzed and contribute to the flame.

The transition between a limited and a more intense decomposition is sharp for both cables but does not occur in the same range. This "transition heat flux" is ranged between 38.5 and $47 \mathrm{~kW} / \mathrm{m}^{2}$ for cable A versus 52 and $57.7 \mathrm{~kW} / \mathrm{m}^{2}$ for cable B. It is noteworthy that Fontaine et al. have not observed such behavior: the total heat released from the burning of a cable at first glance similar to cable $A$ is constant on the whole range of external heat flux investigated $\left(25-75 \mathrm{~kW} / \mathrm{m}^{2}\right)[28]$.

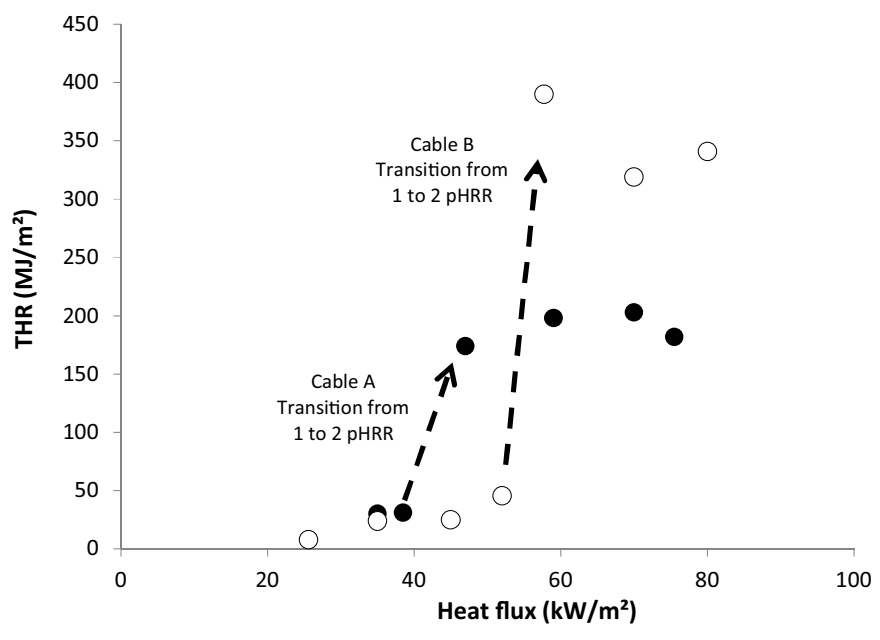

Fig. 8. Total heat release for cables A and B at different heat fluxes. 


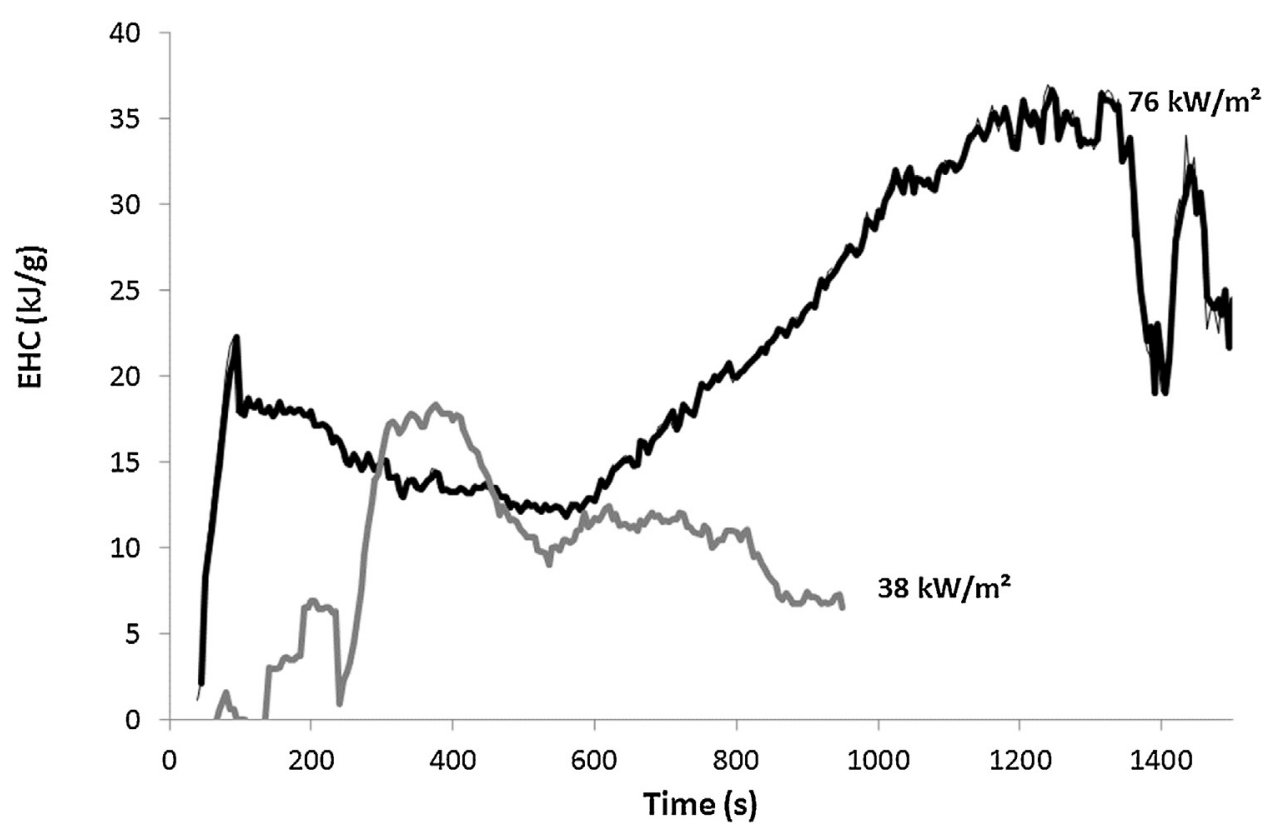

Fig. 9. Effective heat of combustion for cables A at two heat fluxes (curves were smoothed).

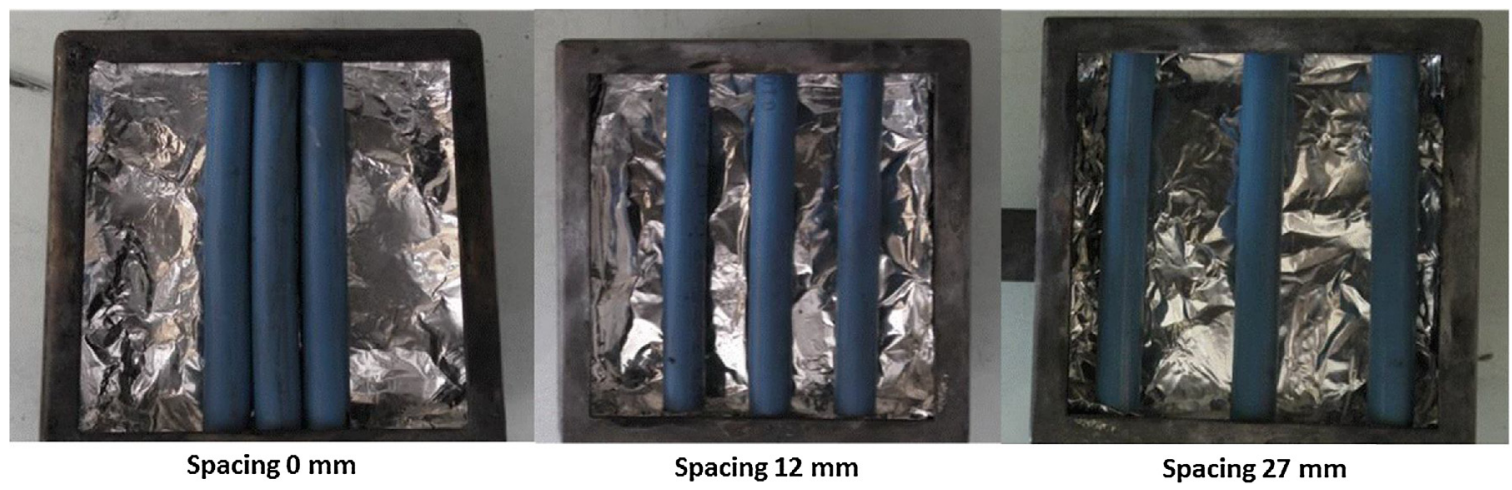

Fig. 10. Position of cables A with changing spacings.

The transition is related to the capacity of the sheath to protect the inner layers of the cable. To confirm this assumption, the effective heat of combustion is plotted in Fig. 9 for the cable A at two heat fluxes (38 and $76 \mathrm{~kW} / \mathrm{m}^{2}$, respectively lower and higher than the transition heat flux). At $38 \mathrm{~kW} / \mathrm{m}^{2}$, EHC does not exceed $18 \mathrm{~kJ} / \mathrm{g}$ and decreases slowly up to flame out. This decrease may mean that the fraction of water (from ATH decomposition, which decomposes from $200^{\circ} \mathrm{C}$, i.e. at a lower temperature than the pyrolysis of EVA and $\mathrm{PE}$ ) in released gases increases continuously. Moreover, it can be assumed that only the outer layer (i.e. the sheath) has been partially pyrolyzed during the test. At $76 \mathrm{~kW} / \mathrm{m}^{2}$ (i.e. above the transition heat flux), the EHC is also in the range $13-20 \mathrm{~kJ} / \mathrm{g}$ during the first $600 \mathrm{~s}$. But when the HRR starts to increase again, EHC also increases up to around $35 \mathrm{~kJ} / \mathrm{g}$. This continuous increase may be due to two phenomena occurring more or less simultaneously. First, ATH is fully decomposed and no water release can dilute the fuels from EVA and PE pyrolysis. It has already been shown that the change in EHC in polymers filled with metallic hydroxides evidences the depletion of water released by the fillers decomposition [35]. Second, the pyrolysis of inner layers starts (as proved by the fact that THR is too high to be only due to the burning of the sheath). However, the inner layers (i.e. mainly PE insulation) are less flame retarded than the sheath. In particular, heat of complete combus- tion for insulation (calculated from PCFC) is much higher than for sheath $(41.1 \mathrm{~kJ} / \mathrm{g}$ versus $19.8 \mathrm{~kJ} / \mathrm{g})$.

The knowledge of the transition heat flux is of first importance in order to predict the fire propagation. Indeed, at low heat flux, the burning concerns only the sheath and the heat released is limited. Above the transition heat flux, the heat release increases six to eight times. This additional release obviously makes fire more hazardous. The transition heat flux is higher for cable B. This may be ascribed to the mass per unit length which is higher for this cable. Indeed, small cables flame retarded with ATH (diameter 6-7 mm - sheath thickness $0.7 \mathrm{~mm}$ or less) do not exhibit such transition. Cables completely burn even at low heat flux (data not shown).

Another parameter in cable tray is of course the spacing between cables. The next section is devoted to the influence of this parameter on the flammability assessed using cone calorimeter tests.

\subsection{Influence of spacing between cables}

The influence of spacing on flammability was studied for cable A. 3 sample cables for cable-type A were used for each experiment. The distance between the cables was ranged between $0 \mathrm{~mm}$ (cables in contact) to $27 \mathrm{~mm}$ (see Fig. 10). The HRR was still calculated considering the whole surface of sample-holder (i.e. $100 \mathrm{~cm}^{2}$ ) even if 


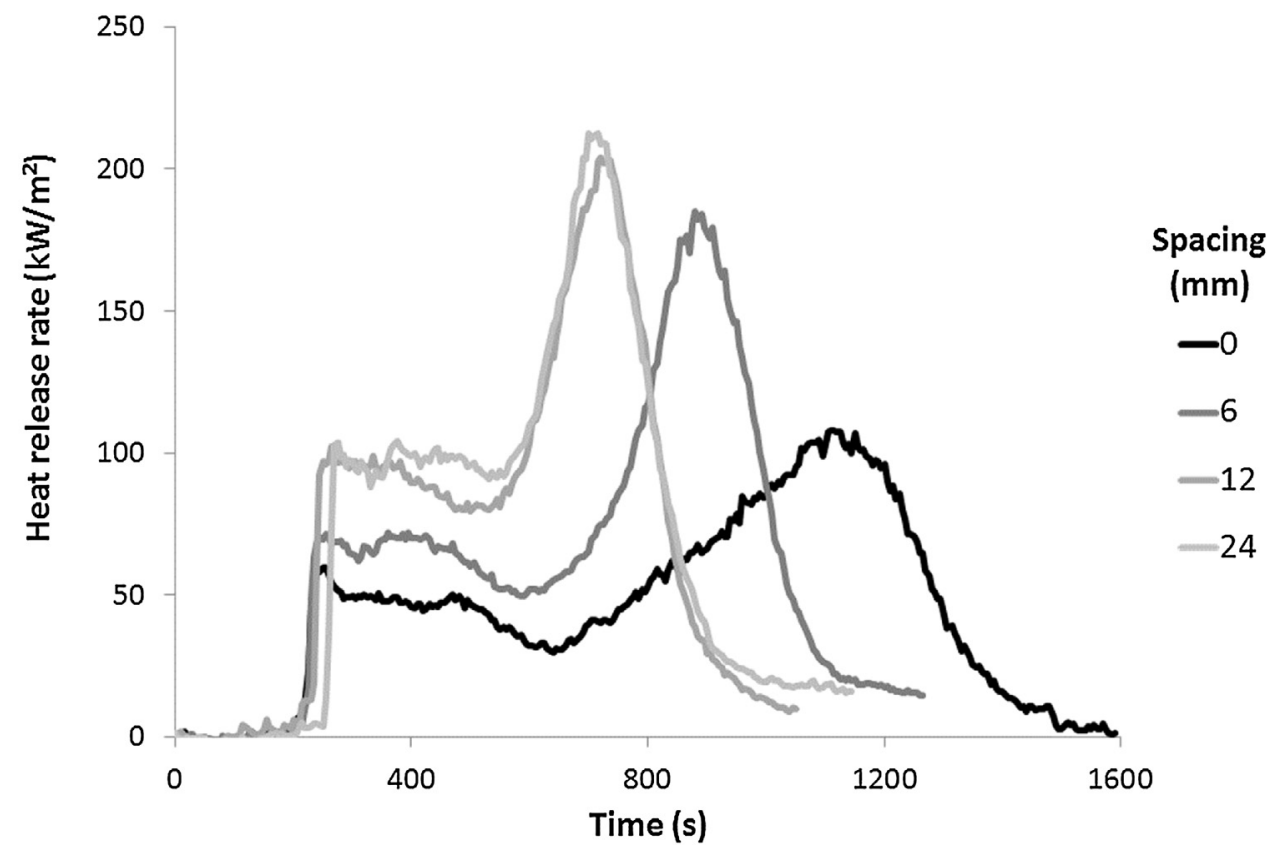

Fig. 11. Heat release rate curves for different distances between cables $A$ (heat flux $40 \mathrm{~kW} / \mathrm{m}^{2}$ ).

the exposed surface of cables was reduced. The tests were carried out at $40 \mathrm{~kW} / \mathrm{m}^{2}$ for the cable A. In these conditions, the HRR curves show two peaks and an intense decomposition of the cables. In other words, the heat flux is higher than the so-called transition heat flux defined previously.

Figs. 11 and 12 show the HRR and EHC versus time for 4 different spacings. Almost all main data are changing with the distance between cables: time-to-ignition, pHRR1, pHRR2 and time to pHRR2 (Figs. 13 and 14). Only total heat release remains almost constant (data not shown): while heat flux is higher than the transition heat flux, the decomposition is very important in all cases and flame out occurs when fuel is depleted. Fig. 12 confirms that EHC increases after $400-700 \mathrm{~s}$ from a low value $(<20 \mathrm{~kJ} / \mathrm{g})$ to $35 \mathrm{~kJ} / \mathrm{g}$ : whichever the spacing, the inner layers of the cables are decomposed. Only the duration to reach the pyrolysis of these layers changes.

The first part of the HRR curve is the least influenced by the spacing. Indeed, time-to-ignition increases only moderately when increasing spacing: from 220 to $280 \mathrm{~s}$. This increase is observed only for spacing higher than $9 \mathrm{~mm}$ (Fig. 13). Below this value, timeto-ignition appears unchanged. PHRR1 also increases from 60 to $110 \mathrm{~kW} / \mathrm{m}^{2}$ when the spacing increases. Taking into account the uncertainties on HRR measurements (typically $15 \%$ on heat release rate), the scattering of results for spacing higher than $9 \mathrm{~mm}$ is not surprising. In all cases, this first pHRR1 is lower than the second pHRR (from $100 \mathrm{~kW} / \mathrm{m}^{2}$ to $200-240 \mathrm{~kW} / \mathrm{m}^{2}$ - see Fig. 14). The ratio between the second and the first peaks is relatively constant, between 1.8 and 2.5 .

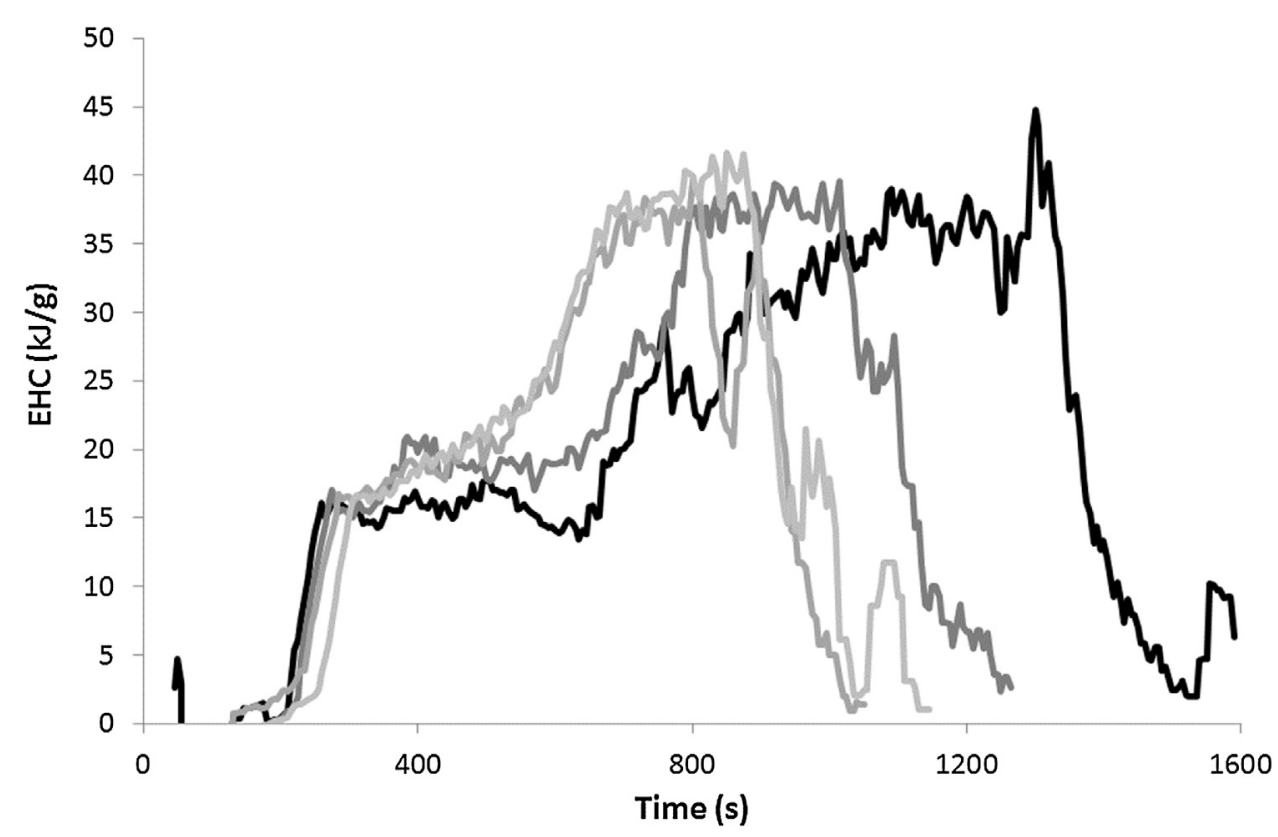

Fig. 12. Effective heat of combustion for different distances between cables $A$ (heat flux $40 \mathrm{~kW} / \mathrm{m}^{2}$ ) (same colors as Fig. 11). 


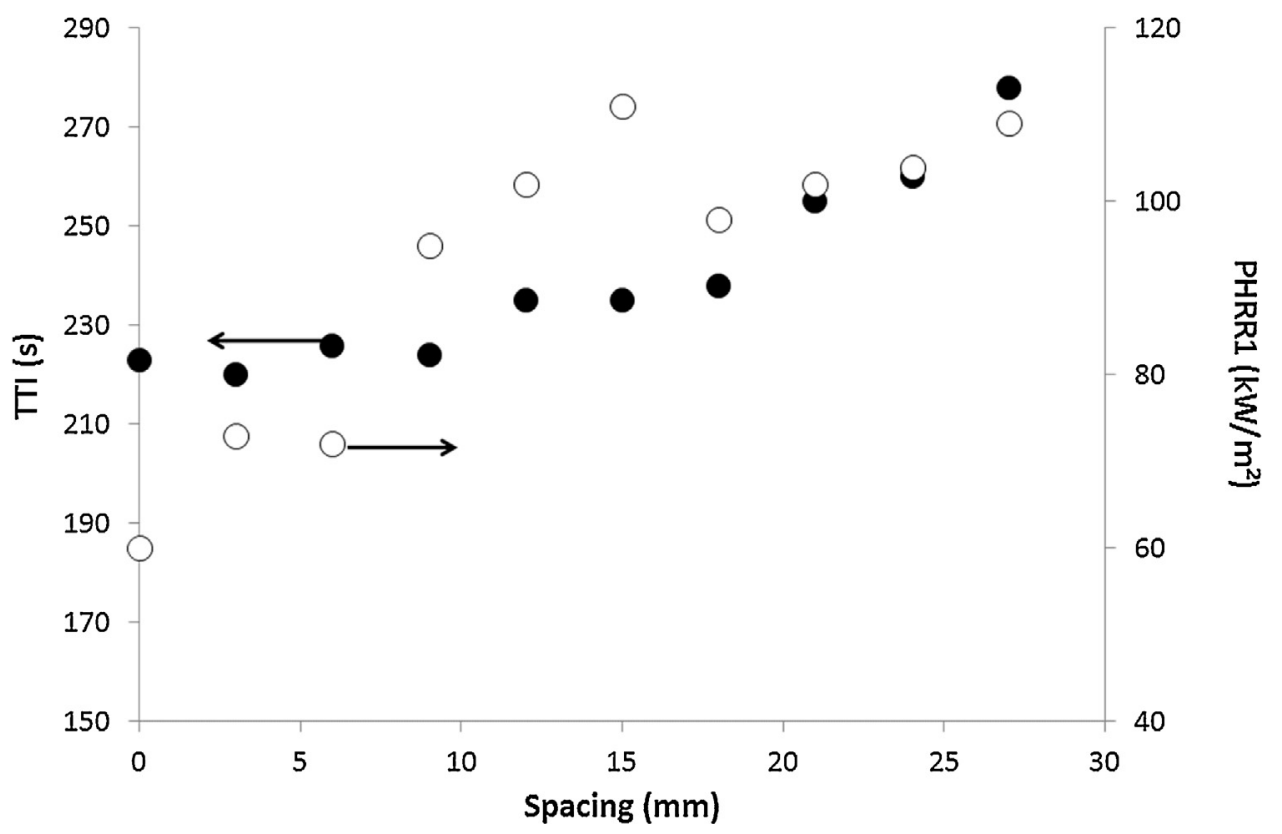

Fig. 13. TTI and pHRR1 for different distances between cables $A$ (heat flux $40 \mathrm{~kW} / \mathrm{m}^{2}$ ).

The second part of the HRR curve is the most influenced by the spacing. In particular, the time to pHRR2 decreases from 1100 to $700 \mathrm{~s}$ when spacing increases (Fig. 14). As for time-to-ignition, this decrease is observed for spacing lower than 9-12 mm. Increasing spacing above this threshold does not change the time to pHRR2 anymore. The scattering of pHRR2 value is important due to the distortion of cables when no grid is used. PHRR2 increases when spacing increases from 0 to $9 \mathrm{~mm}$. Once again, no further increase seems to be apparent for higher spacing.

Spacing has a non-negligible effect on flammability. More precisely, a threshold close to $10 \mathrm{~mm}$ is observed. Most flammability properties are modified when spacing changes below this threshold. Above this threshold the spacing has no more influence except for time-to-ignition. Time-to-ignition starts changing when spac- ing increases above the threshold. This threshold may be rather expressed as a ratio between the spacing and the cable diameter. For cable A (diameter $12 \mathrm{~mm}$ ), the threshold is close to 1 . Other cables must be investigated to confirm this assumption.

Interestingly the spacing has an apparent opposite effect on the different parts of HRR curves. High spacing delays the ignition but increases the peaks of heat release rate and promotes an earlier pHRR2. In the whole, spacing seems to promote a fast decomposition of cables. Further investigations are needed to assess the influence of spacing in greater detail and to understand which phenomenon is precisely modified by spacing. Several assumptions can be listed: spacing may influence the surface exposition to the heat flux, the heat transfer by conduction and/or convection, or the concentration of fuels in the flaming zone.

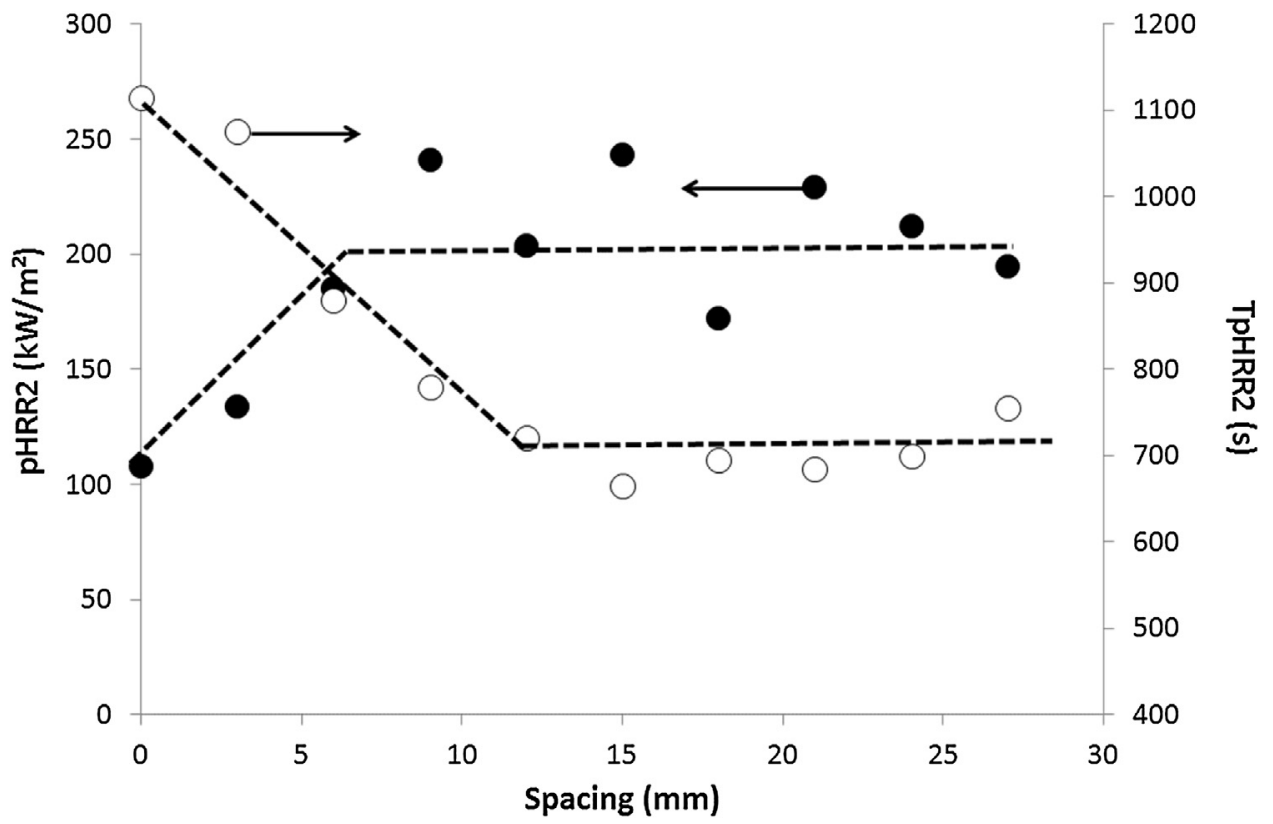

Fig. 14. Time at pHRR2 (TpHRR2) and pHRR2 for different distances between cables A (heat flux $40 \mathrm{~kW} / \mathrm{m}^{2}$ ) - Dotted lines are guidelines to the eye. 


\section{Conclusions}

Two halogen-free flame retardant cables were studied in cone calorimeter by varying the heat flux and the spacing between cables. It appears that the first part of the heat release rate curves (up to $500 \mathrm{~s}$ ) is only driven by the sheath (outer layer) both at low and high heat flux. Indeed, time-to-ignition is well predicted by the so-called thermally thick model considering only the sheath properties. Moreover, the effective heat of combustion is almost constant during the first 500 s of the burning and its value is close to that of the sheath.

However, the fire behavior of the cables is highly dependent on the heat flux. A dramatic transition occurs at a different heat flux according to the cable. Below this heat flux threshold (called transition heat flux), the flame is vanishing before the cable core starts degrading. Above this critical value, the heat release rate increases strongly after 500-1000s leading to a second peak of heat release rate and a much higher heat release. In that case, the inner layers of the cable are decomposing. The knowledge of the transition heat flux is surely of prime importance to predict the fire propagation along cables or cable trays.

The influence of the spacing between cables was also investigated for cable $A$ at a heat flux higher than the transition heat flux. Increasing the distance between cables leads to a slightly higher time-to-ignition and a higher first peak (or plateau) of heat release rate. Moreover, the second pHRR occurs earlier and is much higher. However, above a distance between cables higher than $10 \mathrm{~mm}$, no further influence of spacing is observed for fire properties (except for time-to-ignition).

\section{Contribution to the study of real fires}

Fire safety analyses show that the rooms in NPPs devoted to their operation, control or/and safe-shutdown, such as the switchgear room or the control room, are identified as the main fire hazard contributor locations [36]. As these rooms contain a high concentration of electrical cables mainly distributed in electrical cabinets and in cable trays, a cable fire in such rooms may indeed result in sufficient damage to various safety systems such that the ability to achieve a safe shutdown could be severely challenged. For instance, at the Browns Ferry NPP, over 1600 cables were damaged by the fire and caused short circuits between energized conductors. These short circuits caused certain systems to operate in an unexpected manner [37]. The use of a fire model to forecast the fire spread over cable trays, and the resulting HRR, is thus required to assess the damage on the functionality of various safety-related equipment.

The small-scale data provided in this study on HFFR cables, completed by the large-scale data obtained from the previous cable tray fire tests using same cables [12-14], will thus contribute to the validation of the simple cable fire spread models $[1,4]$ briefly discussed earlier. However these models cannot predict the cable trays ignition that is however a required condition for the proper assessment of the fire spread. Thus, the validation of the time-to-ignition law at small-scale, showed in this investigation for the HFFR cables A and $\mathrm{B}$, will lead us to study it for a real cable tray configuration.

In addition, the transient heat flux, as highlighted in this study, could be correlated to the required time for achieving a selfsustained cable tray fire. Indeed, large-scale fires which used the HFFR cables A and B were considered as self-sustained about 10 and $12 \mathrm{~min}$ after the starting of a gas burner (used as an ignition source) vs about $2 \mathrm{~min}$ for the fires which used halogenated flame retardant cables containing polyvinyl chloride (PVC) [13]. For the latter cables, the transition heat fluxes were estimated as lower than $25 \mathrm{~kW} / \mathrm{m}^{2}$ from tests conducted in the cone calorimeter for a similar PVC cable [1], while they were measured in this study in the $38-58 \mathrm{~kW} / \mathrm{m}^{2}$ range for the former cables. So the larger would be the transient heat flux and the more important would be the required time for achieving a self-sustained fire. Additional experiments at both small and large-scales are needed in order to confirm the above trend for both similar and different cable-types.

Finally, this study also supports the analysis of the fire behavior highlighted at real-scale, such as the EHC time evolutions for the cable trays fire. Indeed, for the cable trays filled with the HFFR cable $\mathrm{B}$, the EHC indicates time evolutions from 10 to about $40 \mathrm{MJ} / \mathrm{kg}$ [14] similar as the ones observed in the cone calorimeter. These last ones are due to the progressive consumption of the ATH (as earlier described in this study) while the fire propagates over the cable trays.

\section{References}

[1] K. McGrattan, A. Lock, N. Marsh, M. Nyden, M. Price, A.B. Morgan, M. Galaska, K. Schenck, Cable Heat Release, Ignition, and Spread in Tray Installations During Fire (Christifire) Volume 1: Horizontal Trays, United States Nuclear Regulatory Commission, Washington DC, 2010.

[2] U.S. NRC, Cable Fire at Browns Ferry Nuclear Power Station, NRC Bulletin BL-75-04, U.S. Nuclear Regulatory Commission, Washington, DC, 1975.

[3] Organisation for Economic Co-operation and Development (OECD), OECD FIRE Database (OECD FIRE DB 2010:1), Nuclear Energy Agency (NEA), 2011.

[4] V. Babrauskas, Heat Release Rates, SFPE Handbook of Fire Protection Engineering, third edition, 2002 (Section three, Chapter 1).

[5] P.S. Sumitra, Categorization of Cable Flammability. Intermediate-Scale Fire Tests of Cable Tray Installations, Interim Report NP-1881, Research Project 1165-1, Factory Mutual research Corp., Norwood, MA, 1982.

[6] A. Tewarson, J. Lee, R. Pion, Categorization of Cable Flammability, Part 1. Experimental Evaluation of Flammability Parameters of Cables Using Laboratory-Scale Apparatus, EPRI Project RP 1165-1, Factory Mutual Research Corp., Norwood, MA, 1979.

[7] ASTM E2058-2013, Standard Test Methods for Measurement of Synthetic Polymer Material Flammability Using a Fire Propagation Apparatus (FPA), American Society for Testing Material, 2013.

[8] ISO 5660, International Standard-Fire Tests-Reaction to Fire-Rate of Heat Release from Building Products (ISO 5660), International Organization for Standardization, Geneva, Switzerland, 1993.

[9] A. Matala, S. Hostikka, Pyrolysis modeling of PVC cable materials, Fire Saf. Sci. 10 (2011) 917-930.

[10] S.I. Stoliarov, S. Crowley, R.E. Lyon, G.T. Linteris, Prediction of the burning rates of non-charring polymers, Combust. Flame 156 (2009) 1068-1083.

[11] C. Lautenberger, C. Fernandez-Pello, Generalized pyrolysis model for combustible solids, Fire Saf. J. 44 (2009) 819-839.

[12] L. Audouin, H. Prétrel, P. Zavaleta, OECD PRISME 2 fire research project (2011-2016) -Current status and perspectives, in: 13th International Seminar on Fire Safety in Nuclear Power Plants and Installations, Columbia, USA, 2013, pp. 69-84.

[13] P. Zavaleta, S. Charbaut, G. Basso, L. Audouin, Multiple horizontal cable tray fire in open atmosphere, in: Thirteenth International Conference of the Fire and Materials, San Francisco, USA, 2013, pp. 57-68.

[14] P. Zavaleta, S. Bascou, S. Suard, Effects of cable tray configuration on fire spread, in: Fifteenth International Conference of the Fire and Materials, San Francisco, USA, 2017, pp. 17-30.

[15] F.X. Rongere, J. Gibault, Numerical Modeling of Fire Propagation: Principles and Applications at Electricite De France, 1994 (Report Number EDF 95NB00068).

[16] A.B. Morgan, J.W. Gilman, An overview of flame retardancy of polymeric materials: application, technology, and future directions, Fire Mater. 37 (2013) 259-279.

[17] M.M. Hirschler, Comparison of large- and small-scale heat release tests with electrical cables, Fire Mater. 18 (1994) 61-76.

[18] M.M. Hirschler, Flame retardants and heat release: review of data on individual polymers, Fire Mater. 39 (2015) 232-258.

[19] M.A. Barnes, P.J. Briggs, M.M. Hirschler, A.F. Matheson, T.J. O’Neill, A comparative study of the fire performance of halogenated and non-halogenated materials for cable applications. Part II tests on cables, Fire Mater. 20 (1996) 17-37.

[20] S.J. Grayson, P. Van Hees, A.M. Green, H. Breulet, U. Vercellotti, Assessing the fire performance of electric cables (FIPEC), Fire Mater. 25 (2001) 49-60.

[21] P. Elliot, R. Whiteley, A cone calorimeter test for the meaurement of flammability properties of insulated wire, Polym. Degrad. Stab. 64 (1999) $577-584$.

[22] C. Huggett, Estimation of rate of heat release by means of oxygen-consumption measurements, Fire Mater. 4 (1980) 61-65.

[23] R.E. Lyon, R.N. Walters, Pyrolysis combustion flow calorimetry, J. Anal. Appl. Pyrolysis 71 (2004) 27-46

[24] D. Hopkins, J. Quintiere, Material fire properties and predictions for thermoplastics, Fire Saf. J. 26 (1996) 241-268 
[25] B. Rhodes, J. Quintiere, Burning rate and flame heat flux for PMMA in a cone calorimeter, Fire Saf. J. 26 (1996) 221-240.

[26] B. Schartel, R. Hull, Development fire-retarded materials -Interpretation of cone calorimeter data, Fire Mater. 31 (2007) 327-354.

[27] R. Sonnier, A. Viretto, L. Dumazert, M. Longerey, S. Buonomo, B. Gallard, C. Longuet, F. Cavodeau, R. Lamy, A. Freitag, Fire retardant benefits of combining aluminum hydroxide and silica in ethylene-vinyl acetate copolymer (EVA) Polym. Degrad. Stab. 128 (2016) 228-236.

[28] G. Fontaine, F.-E. Ngohang, L. Gay, S. Bourbigot, Investigation of the contribution to fire of electrical cable by a revisited mass loss cone, Fire Sci. Technol. (2015) 687-693.

[29] L. Courty, J.P. Garo, External heating of electrical cables and auto-ignition investigation, J. Hazard. Mater. 321 (2017) 528-536.

[30] A. Tewarson, M. Khan, A new standard test method for the quantification of fire propagation behavior of electrical cables using factory mutual research corporation's small-scale flammability apparatus, Fire Technol. 28 (1992) 215-227.

[31] D.A. Boardman, M.M. Khan, The effectiveness of coatings on the flame spread behavior of electric cables, in: Thirteenth International Conference of the Fire and Materials, San Francisco, USA, 2013, pp. 78-87.
[32] M.M. Khan, R.G. Bill, R.L. Alpert, Screening of plenum cables using a small-scale fire test protocol, Fire Mater. 30 (2006) 65-76.

[33] M.A. Delichatsios, Ignition times for thermally thick and intermediate conditions in flat and cylindrical geometries, Fire Safety Science Proceedings of the Sixth International Symposium (1999) 233-244.

[34] F. Cavodeau, R. Sonnier, B. Otazaghine, J.M. Lopez-Cuesta, C. Delaite, Ethylene-vinyl acetate copolymer/aluminium trihydroxide composites: new method to predict the barrier effect during cone calorimeter tests, Polym. Degrad. Stab. 120 (2015) 23-31

[35] R. Sonnier, A. Viretto, L. Dumazert, B. Gallard, A method to study the two-step decomposition of binary blends in cone calorimeter, Combust. Flame 169 (2016) $1-10$

[36] M.H. Salley, R.P. Kassawara, Verification and Validation of Selected Fire Models for Nuclear Power Plant Applications, Volume 1: Main Report, NUREG-1824, NRC and EPRI, U.S, 2007.

[37] S.P. Nowlen, F.J. Wyant, Cable Response to Live Fire (CAROLFIRE), Volume 1: Test Descriptions and Analysis of Circuit Response Data, NUREG/CR-6931, vol. 1, 2008 (April 2008) 